\title{
Priorities of Spinal Cord Injured Population - A Survey
}

\author{
Namrata*, Shazia Mattu \\ Department of Physiotherapy, College of Applied Education and Health Sciences, Meerut, India
}

Email address:

namrataarora20@gmail.com (Namrata),shazia.mattu@gmail.com (S. Mattu)

${ }^{*}$ Corresponding author

To cite this article:

Namrata, Shazia Mattu. Priorities of Spinal Cord Injured Population - A Survey. American Journal of Applied Psychology.

Vol. 6, No. 6, 2017, pp. 183-187. doi: 10.11648/j.ajap.20170606.17

Received: May 22, 2016; Accepted: February 4, 2017; Published: December 19, 2017

\begin{abstract}
In the united states alone, there are more than 200,000 individuals living with a chronic spinal cord injury (SCI). Healthcare for these individuals creates a significant economic burden for the country, not to mention the physical, psychological, and social suffering these people endure every day. Regaining partial function can lead to greater independence, thereby improving quality of life. To ascertain what functions are most important to the SCI population, in regard to enhancing quality of life, a novel survey was performed in which subjects were asked to rank seven functions in order of their importance to their quality of life. The aim of present study was to evaluate the priorities of spinal cord injured population depending on their level of lesion and improvement of which function will make improvement in quality of their life. A total number of 71 subjects were taken. The questionnaire was made to be filled by all the participants through personal interview, Emails and telephonic interviews. There was a significant variation in priorities of spinal cord injured population.
\end{abstract}

Keywords: Quality of Life, Spinal Cord Injury, Priorities

\section{Introduction}

Spinal cord injury (SCI) causes many deficits that often restrict the lives of the individuals as well as their contributions to society. The worldwide impact is dramatic [1]. Many impairments resulting from neurological damage not only limit physical function but also influence an individuals' psychological well-being, social integration, financial status, and life aspirants, to varying degrees [2,3].

Chronic paralysis of all forms, not just spinal cord injury (SCI) is a long term health, economic and social issue worldwide. (national spinal cord injury database, 2001; dijkers et al., 2000). Currently scientists are pressured on many fronts to develop an all encompassing "cure" for paralysis [4].

Although 'curing' all functional deficits associated with SCI is the ultimate end goal of our research, such an endeavor involves much more than repairing, protecting, or regenerating motor tracts- the traditional focus of most related research.

The autonomic nervous system and the sensory system are equally important, yet relatively understudied. Thus research efforts should equally reflect autonomic, sensory and motor contributions to SCI.

In addition it is probable that discoveries leading to incremental improvements in specific functions will occur well before a single, all encompassing 'cure'.

An incremental improvement in neurologic function could translate into a significant improvement in quality of life (QOL) of a person living with SCI. Therefore, we contend that SCI research emphasis should be broadened to develop therapies that contribute directly to QOL.

The SCI community understands and indeed embraces the idea of incremental functional recovery [5]. They have also indicated that walking is not the most important function to recover in order to improve QOL.

Regaining bladder and bowel function, eliminating autonomic dysreflexia (AD), and improving arm/hand function are among the top most priorities of individuals with $\mathrm{SCI}^{5}$, all of which require more extensive research at basic science and clinical level.

Chronic pain and dysesthesia are important and frequent complaints in patients with spinal cord injury (SCI) with a reported prevalence varying between $27 \%$ and $94 \%$ [6-15]. The classification of post- SCI pain is not clarified, which in part may explain the large variation in reported frequency 
[16-18]. The SCI pain task force of IASP broadly classifies SCI pain into nociceptive (musculoskeletal and visceral) and neuropathic (above-level, at-level and below-level) pain [19].

Neuropathic types of pain in SCI may include peripheral (nerves and nerve roots) as well as central components. Neuropathic pain is considered to be a particular bothersome symptom in SCI because it often persists and generally is considered resistant to conventional analgesic treatments.

Neuropathic pain has several distinct features: lesion of nervous tissue, pain in area with sensory deficits, dysesthesia, allodynia, hyperalgesia and abnormal spatial and temporal summation. Several of these features are also seen in SCI pain.

Sexual function is an important part of spinal cord injury (SCI), yet it has traditionally been considered a low priority in regard to research topics and funding. Like many other aspects of SCI, sexual function is influenced by the integrity of motor, sensory, and autonomic pathways as well as psychological and social factors.

Sexual impairments occur to some degree in nearly every SCI and individuals living with SCI rate improving sexual function as a highest priority to improving quality of life [2021].

The two most extensively researched areas in men are erectile dysfunction and ejaculatory compromise in males after SCI. Briefly the neurologic injury level and severity have a significant impact on erectile ability and on the occurrence of reflexogenic or psychogenic erections [22, 23]. The neurogenic injury level and severity have a significant impact on erectile ability and on the occurrence of reflexogenic or psychogenic erections.

Ejaculation is a more complicated process and ejaculation results in a significant number of spinal injured men. Reflexes, somatic responses and electro-physiological parameters have been used to try to predict the ability to successfully induce ejaculation [24, 25].

A significant side effect of assisted ejaculation is that both penile vibro stimulation and electro ejaculation can induce autonomic dysreflexia in men with injuries above T6 [26]. Woman's ability to become pregnant and carry and deliver a child is largely unaffected following spinal cord injury, it was assumed that her sexuality was similarly unaffected. Consequently, female sexuality was equated with child bearing and scientific interest was confined to pregnancy and its complications.

There are various questions that arises in women mind after SCI:

- Does my SCI affect my sexual function?

- What kind of physical changes can I expect?

- Will I have orgasms?

- Will I be able to satisfy my partner?

- What do I do with my catheter during sex?

- What about bowel and bladder accidents?

- Can I still have baby?

- If I decide to have a baby, will I have special problems?

- Are there risks to the baby?

- Will I need a caesarean section for delivery ?[27]
Sustaining a spinal cord injury (SCI) is a life- changing event. There is a physical loss of function as well as psychological, social and economic losses. Having an injury in the cervical spinal cord is even more significant because arm and hand impairments greatly reduce one's ability to care for oneself, which forces one to rely on attendants for daily, life sustaining needs. Relying on attendants is financially over-whelming, unpredictable, and extremely stressful. Regaining arm/hand function has been documented as the highest priority for people with cervical SCI [28-30]. One intervention that exists and has been well-documented to enhance the function is reconstructive surgery of the upper limb through tendon transfers [31-36]. The primary outcomes targeted with these interventions are elbow extension, key pinch, and hook grip. All these are movements vital for the independent performance of multiple activities of daily living (ADL).

A primary goal for rehabilitation is to regain as much function and control of the upper body musculature as possible, to enable everyday life tasks to be performed from a sitting position. In this context the trunk muscles become critical, since they provide the necessary trunk stabilization. Trunk muscles are however, not included in the assessment tool routinely used to classify motor function in persons with SCI, i.e. the International Standard of Neurological Classification of Spinal Cord Injury [37, 38]. Thus, conclusions about motor connectivity to trunk muscles are precluded and classification of the neurological lesion level in persons with thoracic SCI will be based solely on sensory function.. Approximately half of motor recovery occurs within the first 2 months after initial injury, with a decreasing rate after 3 to 6 months. At 2 years after injury, neurologic recovery is assumed to be nearly complete. In patients with an initial motor incomplete SCI, more than $75 \%$ regain some form of ambulatory function. Although conventional rehabilitation programs enhance performance of functional tasks, the loss of strength and coordination substantially limits one's capacity for over ground ambulation training.

\section{Materials and Methods}

\section{Study design: Survey Study}

Methods \& Procedure

The research work has been approved by research committee of college of applied education and health sciences. Spinal cord injured population was taken as subjects. The source of data is from CAEHS OPD, telephonic conversations and through Emails. Subjects were told about the survey and were explained about how to grade their priorities in their native language.

Each and every aspect of questionnaire was explained to subjects clearly as how to answer.

The first question was about their level of injury and in which year it occurred? The second question was targeted to find out their priorities in terms of outcomes. Third question was about their view point to does exercise rehabilitation plays a part in recovery? Fourth question was aimed at 
knowing how active they are to the exercise regime or if they are not accountable to it. Fifth question gathered basic information about the subjects like name, age, gender, contact number, Email ID.

In last question we asked subjects for any further suggestions or comments.

A total number of 71 participants were included in which 38 were quadriplegics and 33 were paraplegics in the age group above 18 years. The subjects signed consent as an approval for their participation in study. Majority of subjects had injury for more than 3 years.

Prior to commencement of data collection subjects were asked to read and acknowledge the consent form.

\section{Result}

There were total number of 73 subjects of spinal cord injury. 38 individuals were quadriplegics and 33 individuals were paraplegics. We have calculated the frequencies of their priorities. Table number 1 showed the first or highest priority of quadriplegics and paraplegics. The first priority of quadriplegics were arm/hand function whereas, for paraplegics first priority was improvement of bladder and bowel function, elimination of dysreflexia.

Table 2 Projects the second highest priority of quadriplegics and paraplegics. Quadriplegics rated the upper body /trunk strength and balance. On the other hand for paraplegics it remain same i.e recovery of bladder and bowel function and elimination of dysreflexia.

Table 1. First priority (paraplegics and quadriplegics).

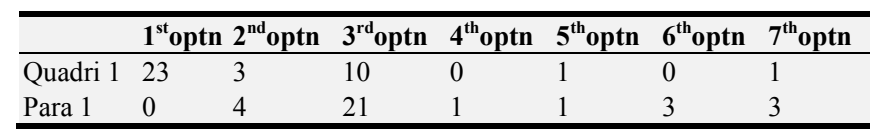

Table 2. Second priority (paraplegics and quadriplegics).

\begin{tabular}{llllllll}
\hline & $\mathbf{1}^{\text {st }}$ optn & $\mathbf{2}^{\text {nd }}$ optn & $\mathbf{3}^{\text {rd }}$ optn & $\mathbf{4}^{\text {th }}$ optn & $\mathbf{5}^{\text {th }}$ optn & $\mathbf{6}^{\text {th }}$ optn & $\mathbf{7}^{\text {th }}$ optn \\
\hline quadri & 12 & 22 & 2 & 0 & 1 & 0 & 1 \\
Para & 0 & 3 & 9 & 4 & 4 & 6 & 7 \\
\hline
\end{tabular}

Table 3. First and second priority quadriplegics and paraplegics (correlation).

\begin{tabular}{llllllll}
\hline Quadri 1 & 23 & 3 & 10 & 0 & 1 & 0 & 1 \\
Quadri 2 & 12 & 22 & 2 & 0 & 1 & 0 & 1 \\
Para 1 & 0 & 4 & 21 & 1 & 1 & 3 & 3 \\
Para 2 & 0 & 3 & 9 & 4 & 4 & 6 & 7 \\
\hline
\end{tabular}

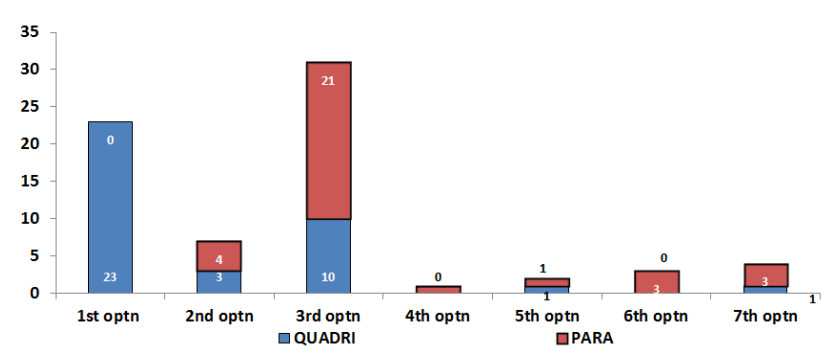

Figure 1. (Depicting table no. 1).

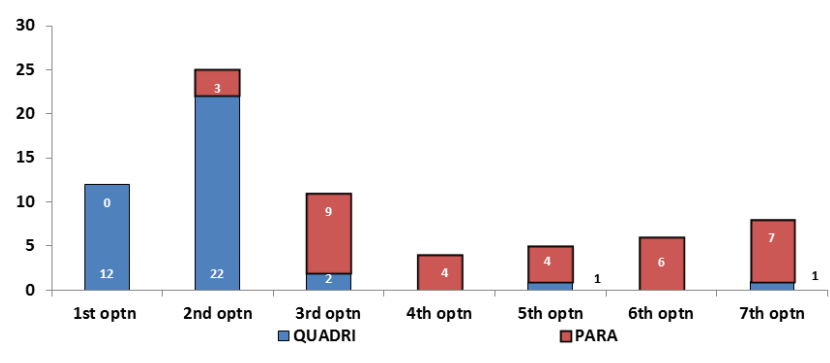

Figure 2. (Depicting table no. 2).

\section{Discussion}

The study was conducted to find out priorities of spinal cord injured population.

A total of 71 number subjects were taken. Of all the participants $54 \%$ were quadriplegics and $46 \%$ were paraplegics.

In addition $15 \%$ female and $75 \%$ male.

\subsection{Priorities of Quadriplegics}

To most appropriately assess the priorities of the SCI population, the responses were grouped into quadriplegics and paraplegics.

For quadriplegics $60 \%$ of the participants indicated that regaining arm and hand function would most improve their quality of life. $26 \%$ ranked bladder $\&$ bowel and elimination of autonomic dysreflexiaregain. 7\% said upper body/ trunk strength and control would improve their quality of life. whereas both elimination of chronic pain and walking movement were priorities of only $2 \%$ and $2 \%$ of the population of a total making $4 \%$.

Sexual function and normal sensation together made a total of only $0 \%$ priority for quadriplegics.

\subsection{Priorities of Paraplegics}

In case of paraplegics participants $63 \%$ ranked bladder\& bowel and elimination of autonomic dysreflexia function to be the most important to their quality of life. This was followed by improving upper body / trunk strength and balance (12\%). Regaining walking movements was higher by paraplegics $(9 \%)$ than by quadriplegics, as was normal sensation (9\%). Sexual function was desirable to only $3 \%$ of the population. elimination of chronic pain ranked higher in quadriplegics (2\%) than paraplegics (1\%).

The data from the survey demonstrate the preferences of the spinal cord injured population in terms of regaining partial functional recovery to the quality of life. The return of arm and hand function was by far the highest priority to quadriplegics. for paraplegics the most desirable function was bladder\& bowel and elimination of autonomic dysreflexia.

Finally the overwhelming majority of all participants regarded exercise as an important part of functional recovery, yet more than half of these did not have access to a trained therapist or proper guide.

Not surprisingly regaining arm and hand function was the most desired function for quadriplegics. This is 
consistent with the fact that recovering even partial arm and hand function can have an enormous impact on independence.

The majority of paraplegics participants regarded bladder $\&$ bowel and elimination of autonomic dysreflexia to be most important to improve their quality of life.

It can take months to years for a person with SCI to develop a reliable, effective bowel routine. The amount of time required to perform a bowel movement can vary from person to person and even from day to day within the same person. Having bowel accidents is not only physically uncomfortable but also socially humiliating. For those individuals whose injury severity requires another person to conduct their bowel management, there are multiple physical, psychological and social humiliations to be endured. Anything that can be done to increase function and independence regarding bladder \& bowel function will be a great advance in medical science.

Another aspect that must be addressed in clinical setting is a long term exercise for chronic SCI. there are some studies demonstrating the benefits of long term exercise in humans with SCI.

Clearly exercise is likely to be beneficial to outcome of SCI. However the results of current study indicate that only of the participants who had access to long-term exercise were supervised by a trained therapist. Aside from already known benefits of exercise to overall health, lack of access to exercise and therapisrs to guide this exercise will be a problem if clinical treatments are developed for SCI which require the reversal of muscle atrophy.

The quality of life of people living with SCI is determined by a range of factors. Not only to health issues, including motor, bowel bladder and sexual function have a substantial impact on the individual well - being, other social aspects of life such as relationships with friends and family members or employment are equally important detriments [39].

\section{Conclusions}

The present study concluded that there was a significant variation in the priorities of spinal cord injured population depending on their level of injury.

- The first priority in quadriplegic population is regaining arm and hand function (60\%).

- The first priority in paraplegic population is improvement in bladder a \& bowel function and elimination of autonomic dysreflexia (63\%).

- The least priority of quadriplegics were regaining sexual function $(0 \%)$.

- The least priority of paraplegics were arm and hand function as they are functionally active $(0 \%)$.

\section{References}

[1] Ackery A, Tator C, Krassioukov A. A global perspective on spinal cord injury epidemiology. J Neurotrauma 2004; 21: $1355-1370$
[2] Stiens SA, Bergman SB, Formal CS. Spinal cord injuryrehabilitation. 4. Individual experience, personal adaptation, and social perspectives. Arch Phys Med Rehabil 1997; 78: S65-S72.

[3] Stiens SA, Kirshblum SC, Groah SL, McKinley WO, Gittler MS. Spinal cord injury medicine. 4. Optimalparticipation in life after spinal cord injury: physical, psychosocial, and economic reintegration into the environment. Arch Phys Med Rehabil 2002; 83: S72-S81.

[4] www. Journal of neurotrauma. Com, volume 21, number 10 , 2004, maryannlibert, inc.

[5] BRINDLEY, G. S. (1994). The first 500 patients with sacral anteriorroot stimulator implants: general description. Paraplegia 32, 795-805.

[6] Nepomuceno $\mathrm{C}$ et al. Pain in patients with spinal cordinjury. Arch Phys Med Rehabil 1979; 60: $605 \pm 609$.

[7] Turner JA, Cardenas DD. Chronic pain problems in individuals with spinal cord injuries. Semin Clin Neuropsychiatry 1999; 4: $186 \pm 194$.

[8] Rose M, Robinson JE, Ells P, Cole JD. Pain following spinal cord injury: results from a postal survey [letter]. Pain 1988; 34: $101 \pm 102$.

[9] Bonica JJ. Introduction: Semantic, Epidemiologic, and Educational Issues. In: Casey KL (ed) Pain and Central Nervous System Disease. First edn. Raven Press: New York 1991, pp $13 \pm 30$.

[10] Fenollosa $\mathrm{P}$ et al. Chronic pain in the spinal cord injured: statistical approach and pharmacological treatment. Paraplegia 1993; 31: $722 \pm 729$.

[11] Anke AG, Stenehjem AE, Stanghelle JK. Pain and lifequality within 2 years of spinal cord injury. Paraplegia 1995; 33: 555 \pm 559 .

[12] Kennedy P, Frankel H, Gardner B, Nuseibeh I. Factorsassociated with acute and chronic pain following traumatic spinal cord injuries. Spinal Cord 1997; 35: $814 \pm 817$.

[13] StormerSet al. Chronic pain/dysaesthesiae in spinal cordinjury patients: results of a multicentre study. Spinal Cord 1997; 35: $446 \pm 455$.

[14] Demirel G, Yllmaz H, Gencosmanoglu B, Kesiktas N. Pain following spinal cord injury. Spinal Cord 1998; 36: $25 \pm 28$.

[15] Rintala DH et al. Chronic pain in a community-basedsample of men with spinal cord injury: prevalence, severity, and relationship with impairment, disability, handicap, and subjective well-being. Arch. Phys. Med. Rehabil. 1998; 79: $604 \pm 614$.

[16] Beric A. Post-spinal cord injury pain states [editorial]. Pain 1997; $72: 295 \pm 298$.

[17] Siddall PJ, Yezierski RP, Loeser JD. Pain following Spinal Cord Injury: Clinical features, Prevalence, and Taxonomy. IASP Newsletter 2000; 3: $3 \pm 7$.

[18] Boivie J. Central Pain. In: Wall PD, Melzack R (eds) Textbook of pain. Third edn. Churchill Livingstone: Edinburgh 1994: pp $871 \pm 902$.

[19] Siddall PJ, Yezierski RP, Loeser JD. Pain following Spinal Cord Injury: Clinical features, Prevalence, and Taxonomy. IASP Newsletter 2000; 3: $3 \pm 7$. 
[20] Anderson KD. Targeting recovery: priorities of thespinal cord injured population. J Neurotrauma 2004; 21: 1371-1383.

[21] Anderson KD, Borisoff JF, Johnson RD, Stiens SA, Elliott SL. The impact of spinal cord injury on sexual function: concerns of the general population. Spinal Cord 2007; 45: 328-337 (this issue).

[22] Biering-S_rensen F, S_nksen J. Sexual function in spinalcord lesioned men. Spinal Cord 2001; 39: 455-470.

[23] Ramos AS, Samso' JV. Specific aspects of erectile dysfunctionin spinal cord injury. Int J Impot Res 2004.

[24] S42-S4516 Bird VG, Brackett NL, Lynne CM, Aballa TC, Ferrell SM. Reflexes and somatic responses as predictors of ejaculationby penile vibratory stimulation in men with spinal cordinjury. Spinal Cord 2001; 39: 514-519.

[25] Courtois F, Geoffrion R, Landry E, Be'langer M. H-Reflexand physiologic measures of ejaculation in men with spinalcord injury. Arch Phys Med Rehabil 2004; 85: 910-918.

[26] Sheel AW, Krassioukov AV, Inglis JT, Elliott SL. Autonomic dysreflexia during sperm retrieval in spinalcord injury: influence of lesion level and sildenafil citrate. J Appl Physiol 2005; 99: 53-58.

[27] www. Craighospital.org.

[28] Hanson RW, Franklin MR. Sexual loss in relation to other functional losses for spinal cord injured males. Arch Phys Med Rehabil 1976; 57: 291-293.

[29] Anderson KD. Targeting recovery: Priorities of the spinalcord injured population. J Neurotrauma 2004; 21: 1371-1383.

[30] Snoek GJ, Ijzerman MJ, Hemens HJ, Biering-Sorensen F. Survey of the needs of patients with spinal cord injury: Impact and priority for improvement in hand function in tetraplegics. Spinal Cord 2004; 42: 526-532.

[31] Freehafter AA, Vonhann E, Allen V. Tendon transfer to improve grasp after injuries of the cervical spinal cord. $j$ Bone Joint Surg 1974; 56A: 951-959.

[32] Moberg e. Surgical treatment for absent single-hand grip and elbow extension in quadriplegia. Principles and preliminary experience. J Bone Joint Surg 1975; 57A: 196-206.

[33] Zacolli E. Surgery for the quadriplegics hand with active, strong wrist extension preserved. A study of 97 cases. Clin Orthop 1975; 112: 101-113.

[34] Lamb DW, Chan KM. Surgical reconstruction of the upper limb in traumatic tetraplegia. A review of 41 patients. J Bone Joint Surg 1983; 65B: 291-298.

[35] House JH, Shannon MA. Restoration of strong grasp and lateral pinch in tetraplegia: a comparsion of two methods of thumb control in each patient. J Hand Surg 1985; 10A: 22-29.

[36] Fride'n J. Tendon Transfers in Reconstructive Hand surgery. Taylor and Francis: Oxford, 2005.

[37] JF JR, Donovan WH, Ducker TB, et al. International standards for neurological and functional classification of spinal cord injury. American Spinal Injury Association. Spinal Cord 1997; 35: 266-274.

[38] Marino RJ, Barros T, Biering - Sorensen F, Burns SP, Donovan WH, Graves De, et al. International standards for neurological classification of spinal cord injury. J Spinal Cord Med 2003; 26 Suppl 1. S50-S 56.

[39] Simpson LA, Eng JJ, Hsieh JT, Wolfe DL. The health and life priorities of individuals with spinal cord injury; a systematic review J Neurotrauma 2012; 29: 424-439. 